\section{RMD Open}

Rheumatic \&

Musculoskeletal Diseases

\title{
Associations of pain sensitisation with tender and painful joint counts in people with hand osteoarthritis: results from the Nor-Hand study
}

\author{
Marthe Gløersen (D) , ,2 Pernille Steen Pettersen, ${ }^{1,2}$ Tuhina Neogi (D) , \\ Barbara Slatkowsky-Christensen, ${ }^{1}$ Tore K Kvien (D) , ${ }^{1,2}$ Karin Magnusson, ${ }^{4,5}$ \\ Hilde Berner Hammer (1) , ${ }^{1,2}$ Ida K Haugen (D) ${ }^{1}$
}

To cite: Gløersen M, Steen Pettersen P, Neogi T, et al. Associations of pain sensitisation with tender and painful joint counts in people with hand osteoarthritis: results from the NorHand study. RMD Open 2022;8:e001774. doi:10.1136/ rmdopen-2021-001774

- Additional supplemental material is published online only. To view, please visit the journal online (http://dx.doi.org/10. 1136/rmdopen-2021-001774).

Received 11 June 2021 Accepted 14 December 2021

Check for updates

(C) Author(s) (or their employer(s)) 2022. Re-use permitted under CC BY-NC. No commercial re-use. See rights and permissions. Published by BMJ.

For numbered affiliations see end of article.

Correspondence to

Marthe Gløersen;

marthe.gl@hotmail.com

\section{ABSTRACT}

Objective To examine associations of pain sensitisation with tender and painful joint counts and presence of widespread pain in people with hand osteoarthritis (OA). Methods Pressure pain thresholds (PPT) at a painful finger joint and the tibialis anterior muscle, and temporal summation (TS) were measured in 291 persons with hand OA. We examined whether sex-standardised PPT and TS values were associated with assessor-reported tender hand joint count, self-reported painful hand and total body joint counts and presence of widespread pain using linear and logistic regression analyses adjusted for age, sex, body mass index, education and OA severity.

Results People with lower PPTs at the painful finger joint (measure of peripheral and/or central sensitisation) had more tender and painful hand joints than people with higher PPTs. PPT at tibialis anterior (measure of central sensitisation) was associated with painful total body joint count (beta $=-0.82,95 \% \mathrm{Cl}-1.28$ to -0.35 ) and presence of widespread pain ( $\mathrm{OR}=0.57,95 \% \mathrm{Cl} 0.43$ to 0.77$)$. The associations between TS (measure of central sensitisation) and joint counts in the hands and the total body were statistically non-significant.

Conclusion This cross-sectional study suggested that pain sensitisation (ie, lower PPTs) was associated with joint counts and widespread pain in hand $0 \mathrm{~A}$. This knowledge may be used for improved pain phenotyping of people with hand $\mathrm{OA}$, which may contribute to better pain management through more personalised medicine. Further studies are needed to assess whether a reduction of pain sensitisation leads to a decrease in tender and painful joint counts.

\section{INTRODUCTION}

Peripheral and central sensitisation contribute to chronic osteoarthritis (OA) pain. ${ }^{1}$ People with OA have lower pressure pain thresholds (PPT) both close to (measure of peripheral and/or central sensitisation) and distant from affected joints (measure of central sensitisation) compared with people without OA. ${ }^{2}$ Temporal

\section{Key messages}

What is already known about this subject?

- Pain sensitisation is associated with greater selfreported hand pain severity in people with hand osteoarthritis $(\mathrm{OA})$.

What does this study add?

- In a hand OA population, we found associations between lower pressure pain thresholds (PPT) at a painful finger joint (indicating a greater degree of pain sensitisation) and more tender and painful hand joints.

- Lower PPTs at the tibialis anterior muscle were associated with presence of widespread pain.

How might this impact on clinical practice or further developments?

- This study adds to the evidence about the relevance of pain sensitisation in hand $\mathrm{OA}$, which may contribute to improve pain management through more personalised medicine in the future.

- Future studies should assess whether a reduction of pain sensitisation is related to less tender and painful joints and less widespread pain in a hand $\mathrm{OA}$ population.

summation (TS), another measure of central sensitisation, and lower PPTs are associated with higher hand pain intensity measured by the Numerical Rating Scale (NRS), but not by the Australian/Canadian OA Hand Index, in people with hand OA. ${ }^{3}$ Tender and painful hand joint counts seem to capture different aspects of pain than the commonly used hand pain questionnaires, ${ }^{4}$ but the relationship between pain sensitisation and tender and painful joint counts has not been previously explored in a hand OA population. Hence, we aimed to examine 
whether PPT and TS were associated with tender and painful joint counts in hands and total body in people with hand OA.

\section{METHODS}

\section{Study participants}

The baseline examination (2016-2017) of the hospitalbased Nor-Hand study included 300 participants with hand OA detected by ultrasound and/or clinical examination. The sample size was pragmatically chosen based on available funding and experience from previous studies. Main exclusion criteria were inflammatory arthritis, psoriasis or haemochromatosis. ${ }^{5}$ The study was approved by the Norwegian Regional Committee for Medical and Health Research Ethics (Ref.no: 2014/2057), and is registered at https://clinicaltrials.gov (NCT03083548).

\section{Quantitative sensory testing}

PPT was tested with a digital handheld algometer (FPIX25, Wagner instruments) by one of two trained medical students. ${ }^{5}$ They were blinded to the results of the clinical joint assessment and questionnaires. At the most painful interphalangeal finger joint (or alternatively the joint with most severe clinical OA with swelling and/or bony enlargements if no joints were painful) the algometer was placed perpendicularly to the dorsal side and pressure was increased by $0.5 \mathrm{~kg} / \mathrm{s}$ until the participant reported slight pain. The procedure was repeated at midportion of the tibialis anterior muscle. The mean values of three measurements at each site were calculated.

TS is characterised by increased pain perception with repetitive stimuli. ${ }^{6}$ Mechanical TS was assessed with seven weighted punctuate probes $(8-512 \mathrm{mN})$ applied to the left distal radioulnar joint with increasing weight until participants rated the pain as $\geq 4$ on the NRS $(0-10)$. This probe, or alternatively the $512 \mathrm{mN}$ if no probe evoked the required pain intensity, was applied 10 times (once per second) to the radioulnar joint. NRS pain at the first, fifth and tenth tap was reported. Pain intensity of the first was subtracted from the highest pain intensity of the fifth and tenth tap.

Nine participants were assessed by both medical students, and inter-assessor reliability was moderate (intraclass correlation coefficients $0.43-0.56$ ) (online supplemental table 1).

\section{Clinical joint assessment}

Fifteen joints in each hand (interphalangeal, metacarpophalangeal and thumb base joints) were assessed for tenderness on palpation of the joint margins according to the Doyle index by a rheumatologist (BS-C) $(n=233$ $(80.1 \%)$ participants) or trained rheumatology fellow. ${ }^{7}$ Joint tenderness was dichotomised (absent $=0$, present=1-3) before calculating the assessor-reported tender hand joint count (range: 0-30).

\section{Self-reported painful joint counts}

Participants marked joints with persistent pain during the prior 6 weeks on a hand diagram depicting the same joints as in the clinical joint assessment. Self-reported painful hand joint count was calculated (range: 0-30).

Persistent pain during the prior 6 weeks in the neck, the upper, middle and lower back and both shoulders, elbows, wrists, hips, knees and ankles was reported on a homunculus. At least one painful joint in each hand counted as a painful hand in the painful total body joint count (range: 0-18). Based on the homunculus, widespread pain was defined as pain in the right and left side of the body, above and below the waist and axial skeletal pain, like in the 1990 definition, except that low back pain was not defined as lower segment pain. ${ }^{8}$

\section{Potential confounders}

Data about age and sex were collected. Questions about highest degree of completed education (seven levels), sleep (five levels, from normal sleep to extreme problems) and regular use of analgesics (oral/topical nonsteroidal anti-inflammatory drugs, acetaminophen and opioids/ opioid-like drugs) were answered in addition to the Hospital Anxiety and Depression Scale (HADS) (range: 0-42) and the Pain Catastrophizing Scale (PCS) (range: 0-52). ${ }^{9}{ }^{10}$ Body mass index (BMI) was calculated from measured height and weight.

Radiographic hand OA severity in 32 joints was determined by a trained physician (IKH) using a modified Kellgren-Lawrence scale (sum score with range: $0-128) .{ }^{11}$

Based on the ultrasound examination of the lower extremities performed by a trained medical student, ${ }^{5}$ we calculated an osteophyte sum score including both hips, maximum score of four compartments in each knee and highest score of all joints in each ankle/foot (range: $0-18)$.

\section{Statistical analyses}

Sex-standardised PPT and TS values were calculated by subtracting the mean from the observed value and divide by the standard deviation for men and women separately, due to sex differences in pain sensitivity. ${ }^{12}$ Associations with tender and painful joint counts and presence of widespread pain were assessed with linear and logistic regression analyses. Analyses were adjusted for age, sex, BMI, education and radiographic hand OA (parsimonious model), and additionally for osteophytes in lower extremities when total body joint count and widespread pain were outcomes. A sensitivity analysis was conducted by adding sleep, HADS, PCS and use of analgesics as potential confounders (comprehensive model). These variables may affect pain, but may also be consequences of pain. Missing values in potential confounders were replaced with mean values. Stata/IC V.14.0 was used, and $p<0.05$ was considered statistically significant. 


\begin{tabular}{|c|c|}
\hline Age, median (IQR) years & $61(57-66)$ \\
\hline Women, n (\%) & $257(88)$ \\
\hline Fulfilment of ACR hand OA criteria, $\mathrm{n}(\%)$ & $271(93)$ \\
\hline Duration of symptoms, median (IQR) years* & $6(3-13)$ \\
\hline Body mass index, mean (SD) kg/m² & $26.4(4.8)$ \\
\hline $\begin{array}{l}\text { Assessor-reported tender hand joint count } \\
(0-30), \text { median }(\mathrm{IQR}) \text { joints }\end{array}$ & $7(4-11)$ \\
\hline $\begin{array}{l}\text { Self-reported painful hand joint count }(0-30) \text {, } \\
\text { median (IQR) joints }\end{array}$ & $4(2-8)$ \\
\hline $\begin{array}{l}\text { Self-reported painful total body joint count } \\
(0-18), \text { median (IQR) joints }\end{array}$ & $4(2-8)$ \\
\hline Presence of widespread pain, n (\%) & $104(35.7)$ \\
\hline PPT painful finger joint, mean (SD) $\mathrm{kg} / \mathrm{cm}^{2}$ & $3.9(1.9)$ \\
\hline PPT tibialis anterior muscle, mean (SD) $\mathrm{kg} / \mathrm{cm}^{2}$ & $5.5(2.6)$ \\
\hline Temporal summation, median (IQR) & $1(0-2)$ \\
\hline $\begin{array}{l}\text { Educational level, } \mathrm{n}(\%) \text { with university or } \\
\text { other higher education* }\end{array}$ & $168(58)$ \\
\hline $\begin{array}{l}\text { Sleep disturbances, } \mathrm{n}(\%) \text { with moderate to } \\
\text { extreme sleep impairment }{ }^{\star}\end{array}$ & $119(41)$ \\
\hline Regular use of analgesics, n (\%) & $45(15)$ \\
\hline HADS total score (0-42), median (IQR)* & $6(3-10)$ \\
\hline PCS total score (0-52), median (IQR)* & $9(5-15)$ \\
\hline $\begin{array}{l}\text { Kellgren-Lawrence sum score (0-128), median } \\
\text { (IQR) }\end{array}$ & $28(16-43)$ \\
\hline $\begin{array}{l}\text { Sum score of ultrasound-detected } \\
\text { osteophytes in bilateral hips, knees and } \\
\text { ankles/feet (0-18), median (IQR) }\end{array}$ & $4(2-7)$ \\
\hline
\end{tabular}

*Missing values: duration of symptoms $n=21$, educational level $n=1$, sleep disturbances $n=1$, HADS total score $n=9$, PCS total score $n=4$.

ACR, American College of Rheumatology; HADS, Hospital Anxiety and Depression Scale; PCS, Pain Catastrophizing Scale; PPT, pressure pain threshold.
RESULTS

We excluded nine persons because of missing quantitative sensory testing (QST) (equipment error). Demographics of the 291 included participants are reported in table 1. In both the parsimonious and the comprehensive model, people with lower PPTs at the painful finger joint had more tender and painful hand joints than people with higher PPTs. Similarly, lower PPTs at tibialis anterior were associated with more painful joints in the total body and presence of widespread pain (table 2 and online supplemental table 2). A trend towards an association between TS and widespread pain was found in the parsimonious model only.

\section{DISCUSSION}

In our study, associations were found between PPT at the painful finger joint (measure of peripheral and/ or central sensitisation) and tender and painful hand joint counts. Associations between PPTs and tender joint count have also been reported in patients with rheumatoid arthritis (RA). ${ }^{1314}$ This has not been previously investigated in hand OA, although joint counts are potential measures of joint activity like in RA. ${ }^{15}$

Lower PPTs at tibialis anterior were associated with higher painful total body joint count and presence of widespread pain. Our study is the first to demonstrate that central sensitisation is associated with widespread pain in people with hand OA. Two knee OA studies found that lower PPTs at local and remote sites, but not TS, correlated with more painful sites and larger painful areas of the total body. ${ }^{16}$ Correspondingly, we found no statistically significant associations between TS and joint counts, but there was a tendency in the parsimonious model that people with TS had more widespread pain. People with concomitant widespread pain had increased TS compared with people with knee OA only in a recent study. ${ }^{18}$ The somewhat conflicting results between PPT at tibialis anterior and TS in our study may be partly due to the moderate reliability of the QST.

Table 2 Associations of sex-standardised pressure pain thresholds and temporal summation with assessor-reported tender and self-reported painful joint counts (parsimonious model)*

\begin{tabular}{|c|c|c|c|c|}
\hline & $\begin{array}{l}\text { Assessor-reported } \\
\text { tender hand joint } \\
\text { count }(0-30)\end{array}$ & $\begin{array}{l}\text { Self-reported } \\
\text { painful hand joint } \\
\text { count }(0-30)\end{array}$ & $\begin{array}{l}\text { Self-reported painful } \\
\text { total body joint count } \\
(0-18)\end{array}$ & $\begin{array}{l}\text { Presence of } \\
\text { widespread pain } \\
\text { (yes/no) }\end{array}$ \\
\hline & Beta $(95 \% \mathrm{Cl})$ & Beta $(95 \% \mathrm{Cl})$ & Beta $(95 \% \mathrm{Cl})$ & OR $(95 \% \mathrm{Cl})$ \\
\hline PPT painful finger joint & $-0.78(-1.39$ to -0.17$)$ & $\begin{array}{l}-0.83(-1.58 \text { to } \\
-0.08)\end{array}$ & $-0.55(-1.03$ to -0.07$)$ & 0.81 (0.61 to 1.06 ) \\
\hline PPT tibialis anterior & $-0.67(-1.27$ to -0.06$)$ & $-0.40(-1.14$ to 0.34$)$ & $-0.82(-1.28$ to -0.35$)$ & 0.57 (0.43 to 0.77$)$ \\
\hline Temporal summation & $0.32(-0.29$ to 0.92$)$ & $0.45(-0.29$ to 1.19$)$ & $0.38(-0.09$ to 0.85$)$ & 1.24 (0.96 to 1.60$)$ \\
\hline
\end{tabular}

*Adjusted for age, sex, body mass index, education and severity of osteoarthritis. Analyses are presented per SD increase in PPT/temporal summation (SD PPT painful finger joint women: 1.93, men: 1.77, SD PPT tibialis anterior women: 2.45, men: 2.93, SD temporal summation women: 1.61, men: 1.21). Statistically significant associations are shown in bold.

PPT, pressure pain threshold. 
Associations were weaker in the comprehensive model, which may indirectly mean that the potential confounders included in this model may be of relevance. However, the direction of the relation between pain and these variables is debatable, and these results should therefore be treated with caution.

Our results suggest that pain sensitisation is clinically relevant in a hand OA population. However, the minimal clinically important difference of joint counts is unknown and needs to be explored in future studies. Improved knowledge about pain phenotypes is required for better pain management through more personalised medicine. Pain sensitisation is recommended as a potential stratification tool in clinical knee OA trials. ${ }^{19}$ We propose that future clinical hand OA trials should include a similar recommendation.

This study is limited by cross-sectional data, which makes cautious interpretation of the directions of the relationships necessary. Although the same detailed protocol was followed by trained examiners, the reliability of the QST was not optimal. The moderate inter-assessor reliability might have influenced our results, although associations remained similar when repeated with assessments conducted by the examiner that performed most assessments $(73.5 \%)$. The moderate reliability may have led to misclassification of the participants. With improved reliability we could have found more consistent statistically significant associations with joint counts and widespread pain for all QST measures. More training of the examiners, more participants included in the reliability exercise and more focus on concentration and cooperation are important to provide better reliability of QST in future studies. Participants were recruited from secondary care, which may limit the generalisability of the results.

In conclusion, pain sensitisation, measured by lower PPTs, was associated with more tender and painful joints in the hands and the total body in people with hand OA. Our results indicate that tender and painful joint counts are related not only to local disease processes, but also to pain sensitisation. Central sensitisation also seems to be associated with widespread pain in people with hand OA. Pain sensitisation should receive attention in the search for better pain management of these patients.

\section{Author affiliations \\ ${ }^{1}$ Division of Rheumatology and Research, Diakonhjemmet Hospital, 0slo, Norway \\ ${ }^{2}$ Faculty of Medicine, University of Oslo, Oslo, Norway \\ ${ }^{3}$ Section of Rheumatology, Boston University School of Medicine, Boston, Massachusetts, USA \\ ${ }^{4}$ Faculty of Medicine, Department of Clinical Sciences Lund, Orthopaedics, Clinical Epidemiology Unit, Lund University, Lund, Sweden \\ ${ }^{5}$ Cluster for Health Services Research, Norwegian Institute of Public Health, Oslo, Norway}

Acknowledgements We would like to thank the participants, the project coordinators Janicke Magnus and Elisabeth Mulrooney and physicians and research assistants in the Nor-Hand study. We also thank the medical student Caroline M Fjellstad for performing the ultrasound examination of the lower extremities, as well as the medical students Julie Bergh and Malin Eijsink for performing the quantitative sensory testing.
Contributors MG: substantial contributions to acquisition, analysis and interpretation of data and drafting the work. PSP: substantial contributions to analysis and interpretation of data and revising the manuscript critically for important intellectual content. TN: substantial contributions to the study design, interpretation of data and revising the manuscript critically for important intellectual content. BS-C: substantial contributions to acquisition and interpretation of data and revising the manuscript critically for important intellectual content. TKK: substantial contributions to the study design, interpretation of data and revising the manuscript critically for important intellectual content. KM: substantial contributions to the study design, acquisition and interpretation of data and revising the manuscript critically for important intellectual content. HBH: substantial contributions to the study design, interpretation of data and revising the manuscript critically for important intellectual content. IKH: substantial contributions to the study design, acquisition, analysis and interpretation of data and revising the manuscript critically for important intellectual content. All authors approved the final manuscript to be submitted and agreed to be accountable for all aspects of the work in ensuring that questions related to the accuracy or integrity of any part of the work are appropriately investigated and resolved. IKH takes full responsibility for the finished work and the conduct of the study, had full access to the data in the study and controlled the decision to submit for publication.

Funding This work was supported by grants from Major and Lawyer Eivind Eckbo's Foundation. The data collection of the Nor-Hand study was supported by grants from the South-Eastern Norway Regional Health Authority, Dr Trygve Gythfeldt and wife's Research Foundation, Pahle's Foundation and Simon Fougner Hartmann's Family Foundation. Tuhina Neogi was supported by NIH K24 AR070892 The funders did not have any role in the study design, collection, analysis or interpretation of data.

Competing interests TKK reports grants and personal fees from AbbVie, grants from BMS, grants and personal fees from MSD, personal fees from Hospira/Pfizer, personal fees from Roche, grants and personal fees from UCB, personal fees from Eli-Lilly, personal fees from Hikma, personal fees from Orion, personal fees from Sanofi, personal fees from Celltrion, personal fees from Sandoz, personal fees from Biogen, personal fees from Amgen, personal fees from Egis, personal fees from Ewopharma, personal fees from Mylan, personal fees from Evapharma, outside the submitted work. HBH reports personal fees from AbbVie, personal fees from Novartis, personal fees from Lilly, outside the submitted work. IKH reports grants from Pfizer and personal fees from Novartis, outside the submitted work. MG, PSP, TN, BS-C and KM have nothing to disclose.

\section{Patient consent for publication Not applicable.}

Ethics approval This study involves human participants and was approved by the Norwegian Regional Committee for Medical and Health Research Ethics (Ref.no: 2014/2057). Participants gave informed consent to participate in the study before taking part.

Provenance and peer review Not commissioned; externally peer reviewed.

Open access This is an open access article distributed in accordance with the Creative Commons Attribution Non Commercial (CC BY-NC 4.0) license, which permits others to distribute, remix, adapt, build upon this work non-commercially, and license their derivative works on different terms, provided the original work is properly cited, appropriate credit is given, any changes made indicated, and the use is non-commercial. See: http://creativecommons.org/licenses/by-nc/4.0/.

\section{ORCID iDs}

Marthe Gløersen http://orcid.org/0000-0003-2233-4370

Tuhina Neogi http://orcid.org/0000-0002-9515-1711

Tore K Kvien http://orcid.org/0000-0002-8441-3093

Hilde Berner Hammer http://orcid.org/0000-0001-7317-8991

Ida K Haugen http://orcid.org/0000-0001-7810-2216

\section{REFERENCES}

1 Arendt-Nielsen L. Pain sensitisation in osteoarthritis. Clin Exp Rheumatol 2017;35:S68-74

2 Suokas AK, Walsh DA, McWilliams DF, et al. Quantitative sensory testing in painful osteoarthritis: a systematic review and metaanalysis. Osteoarthritis Cartilage 2012;20:1075-85.

3 Steen Pettersen P, Neogi T, Magnusson K, et al. Peripheral and central sensitization of pain in individuals with hand osteoarthritis and associations with self-reported pain severity. Arthritis Rheumatol 2019;71:1070-7.

4 Kroon FPB, Damman W, van der Plas JL, et al. Self-Reported painful joint count and assessor-reported tender joint count as instruments to assess pain in hand osteoarthritis. Rheumatology 2020;59:1094-8. 
5 Gløersen M, Mulrooney E, Mathiessen A, et al. A hospital-based observational cohort study exploring pain and biomarkers in patients with hand osteoarthritis in Norway: the Nor-Hand protocol. BMJ Open 2017;7:e016938.

6 Curatolo M, Petersen-Felix S, Arendt-Nielsen L. Sensory assessment of regional analgesia in humans: a review of methods and applications. Anesthesiology 2000;93:1517-30.

7 Doyle DV, Dieppe PA, Scott J, et al. An articular index for the assessment of osteoarthritis. Ann Rheum Dis 1981;40:75-8.

8 Wolfe F, Smythe HA, Yunus MB, et al. The American College of rheumatology 1990 criteria for the classification of fibromyalgia. Report of the multicenter criteria Committee. Arthritis Rheum 1990;33:160-72.

9 Zigmond AS, Snaith RP. The hospital anxiety and depression scale. Acta Psychiatr Scand 1983;67:361-70.

10 Sullivan MJL, Bishop SR, Pivik J. The pain catastrophizing scale: development and validation. Psychol Assess 1995;7:524-32.

11 Haugen IK, Englund M, Aliabadi P, et al. Prevalence, incidence and progression of hand osteoarthritis in the general population: the Framingham osteoarthritis study. Ann Rheum Dis 2011;70:1581-6.

12 Sorge RE, Totsch SK. Sex differences in pain. J Neurosci Res 2017;95:1271-81.

13 Lee YC, Bingham CO, Edwards RR, et al. Association between pain sensitization and disease activity in patients with rheumatoid arthritis: a cross-sectional study. Arthritis Care Res 2018;70:197-204.

14 Joharatnam N, McWilliams DF, Wilson D, et al. A cross-sectional study of pain sensitivity, disease-activity assessment, mental health, and fibromyalgia status in rheumatoid arthritis. Arthritis Res Ther 2015;17:11.

15 Kloppenburg M, Maheu E, Kraus VB, et al. OARSI clinical trials recommendations: design and conduct of clinical trials for hand osteoarthritis. Osteoarthritis Cartilage 2015;23:772-86.

16 Moore RL, Clifford AM, Moloney N, et al. The relationship between clinical and quantitative measures of pain sensitization in knee osteoarthritis. Clin J Pain 2020;36:336-43.

17 Lluch Girbés E, Dueñas L, Barbero M, et al. Expanded distribution of pain as a sign of central sensitization in individuals with symptomatic knee osteoarthritis. Phys Ther 2016;96:1196-207.

18 Guérard O, Dufort S, Forget Besnard L, et al. Comparing the association of widespread pain, multi-joint pain and low back pain with measures of pain sensitization and function in people with knee osteoarthritis. Clin Rheumatol 2020;39:873-9.

19 McAlindon TE, Driban JB, Henrotin Y, et al. OARSI clinical trials recommendations: design, conduct, and reporting of clinical trials for knee osteoarthritis. Osteoarthritis Cartilage 2015;23:747-60. 